\title{
NOS CAMINHOS PARA O NORDESTE: REFLEXÕES SOBRE OS IMPACTOS DIRETOS E INDIRETOS DA MIGRAÇÃO DE RETORNO NO PERÍODO RECENTE
}

\section{PATHWAYS TO NORTHEAST: CONSIDERATIONS ON DIRECT AND INDIRECT IMPACTS OF RETURN MIGRATION IN RECENT TIME}

\author{
Ricardo Ojima \\ Universidade Federal do Rio Grande do Norte - Natal - RN - Brasil \\ Tiago Carlos Lima do Nascimento \\ Universidade Federal de Minas Gerais - Belo Horizonte - MG - Brasil
}

\begin{abstract}
Resumo: Analizou-se as recentes mudanças nos fluxos migratórios no Brasil, mais especificamente, a crescente importância da migração de retorno e os seus efeitos indiretos para o Nordeste brasileiro. A partir dos dados censitários recentes, observou-se a importância dos fluxos de retorno migratório para o Nordeste e como os membros dessas famílias de pessoas retornadas (i.e. seus efeitos indiretos) contribuem para os fluxos migratórios em direção ao Nordeste. Assim, esta análise permite reconhecer os migrantes, enquanto grupo social, observando as suas principais características. A caracterização desses fluxos se configura como elemento importante para entender os novos espaços de migração no Brasil, especialmente a região Nordeste.

Palavras-chave: Migração. Desenvolvimento Regional. Migração de Retorno. Efeitos Indiretos da Migração de Retorno.
\end{abstract}

Abstract: We seek to analyze the relationship with the recent changes in migration flows in Brazil, more specifically, the increasingly importance of return migration and its indirect effects, with special emphasis on the Brazilian Northeast. Through recent demographic census data it was observed the importance of return migration flows to Northeast and from family members of these returned persons (i.e. the indirect effects). Thus, this analysis allows us to recognize migrants as a social group, noting their main characteristics. The characterization of these flows is configured as an important element in new spaces of migration in Brazil, especially for the Northeast.

Keywords: Migration, Regional Development, Return Migration, Indirect Effects of Return Migration.

\section{INTRODUÇÃO}

O processo de urbanização brasileira ocorreu de forma bastante intensa entre as décadas de 1940 e 1970. As mudanças nas formas de produção causadas pelo intenso processo de industrialização articulado pelo capital privado e o Estado fizeram que, nesse interstício de tempo, a população brasileira deixasse de ser predominantemente rural para majoritariamente urbana (OLIVEIRA, 1987). A implantação do latifúndio nas antigas estruturas agrárias brasileiras e 0 consequente processo de expropriação das terras dos trabalhadores influenciaram diretamente os grandes fluxos migratórios para os grandes centros urbanos, isto é, para as capitais brasileiras (SILVA, 1998). Desse modo, as cidades brasileiras obtiveram esse perfil de grande crescimento populacional nas suas capitais que, 
por sua vez, detinham o poder de concentração de capital, de reprodução da força de trabalho e, consequentemente, uma grande capacidade de absorção da força de trabalho capaz de atrair os fluxos migratórios.

Contudo, nas últimas décadas, o Brasil vem experimentando mudanças nesse processo de concentração populacional, um aumento na diversidade das atividades de produção no entorno dos tradicionais centros metropolitanos e, também, um crescimento na fluidez dos meios de transporte, do capital e das pessoas, proporcionados pelo avanço da técnica. Assim, novos espaços de migração emergem no cenário nacional (BAENINGER, 2008; BAENINGER; OJIMA, 2008), proporcionando cenários de mobilidade espacial da população mais complexos e diversificados.

O espaço vem se tornando mais complexo, sendo necessário que se faça análises regionais integradas para dar conta dessas novas relações espaciais desiguais, muitas vezes excludentes, desarticuladas e, ao mesmo tempo, dependentes uma das outras (MASSEY, 2012). Considerando que a migração é um fenômeno social, espacial e demográfico, isto é, possui uma vasta gama de elementos que são necessários para sua compreensão, faz-se necessário pensar as espacialidades do migrante, as espacialidades no local de destino, no local de origem e, também, as espacialidades quando se deu a "decisão" de migrar (CUNHA, 2011). Torna-se, assim, premente a leitura de elementos contextuais dos migrantes, principalmente após a reestruturação dos espaços urbanos brasileiros e a importância desse fenômeno no processo histórico-social atual no que se refere à redistribuição espacial da população brasileira (BAENINGER, 2011).

A análise regional se destaca nos estudos sobre a redistribuição da população por considerar as espacialidades em sua totalidade, por meio da análise dos elementos ambientais, econômicos, sociais e culturais de forma integrada e como esses elementos interagem entre si. Por meio desse escopo, o artigo busca analisar um dos aspectos que tem se tornado mais evidente e significativo dentro dos novos arranjos dos fluxos migratórios recentes: a migração de retorno (RIBEIRO, 1997).

A migração de retorno costuma ser caracterizada quando um indivíduo original de uma determinada Unidade da Federação-UF, após uma etapa migratória em outra UF por um determinado período de tempo, retorna para a mesma UF de origem. Os dados censitários permitem descrever essa modalidade de retorno migratório e tem assumido importância cada vez maior nos fluxos migratórios regionais (OLIVEIRA; OLIVEIRA, 2011; FUSCO; DUARTE, 2010), especialmente para o Nordeste. Assim, o artigo fará uma breve análise do contexto migratório da região Nordeste do país para, posteriormente, avançar no entendimento da migração de retorno e seu papel no contexto regional. Para tanto, será considerado na análise o migrante retornado, mas também os impactos indiretos desses migrantes de retorno.

Assim, serão analisados dois elementos relacionados à migração de retorno: as características dos migrantes retornados e o que será chamado de "efeito indireto", que seriam os imigrantes associados aos migrantes retornados. Estes últimos seriam os indivíduos que residiam no local de destino da migração, junto ao migrante de retorno. Nesse sentido, conclui-se que a migração de retorno tem um papel mais significativo ainda, pois, devido a sua seletividade específica nesses 
casos de retorno, altera importantes características da dinâmica demográfica e social nas regiões de destino.

\section{A MIGRAÇÃO NO NORDESTE: BREVE RETROSPECTO}

O Nordeste também é conhecido como um tradicional centro expulsor de população. Em geral, com baixos indicadores de desenvolvimento social e de esperança de vida, a população nordestina tende a se concentrar de forma polarizada em determinados municípios, sobretudo nas capitais litorâneas. Tais aspectos tendem a criar no imaginário social duas percepções estigmatizadas da região Nordeste: uma relacionada às regiões carentes, marcadas pelas secas recorretes; e outra, associada às suas praias e aspectos naturais turísticos. Entretanto, há muito mais heterogeneidades intrarregionais do que essa construção permitiria analisar.

Nesse contexto, as migrações no Brasil tiveram uma forte associação com a mobilidade social, portanto, o caminho para os grandes centros urbanos articulava uma possibilidade evidente de ascensão social para o indivíduo migrante com forte relação ao contexto de industrialização e urbanização. Portanto, a migração ruralurbana contribuiu para a mobilidade social ascendente nesse período das grandes migrações interestaduais das décadas de 1960 e 1970 (PASTORE, 1979; CANELAS, 1980; JANNUZZI, 1999).

Ao considerar todo o território nacional, observa-se um arrefecimento dos fluxos migratórios nas últimas décadas por meio da redução de $11 \%$ entre os quinquênios $^{1} 1995$ - 2000 e 2005 - 2010: 5.196 .093 e 4.643 .754 migrantes, respectivamente (IBGE, 2013). Os fluxos migratórios envolvendo as UFs nordestinas apresentaram diversas mudanças. As UF do Maranhão, Alagoas e Piauí mantiveram suas perdas migratórias constantes. O Ceará apresentou maiores taxas de saída de população devido a uma menor capacidade do estado em atrair migrantes. As UF da Paraíba, Pernambuco e Bahia diminuíram as suas taxas negativas de migração no quinquênio 2005 - 2010. O Rio Grande do Norte dobrou o seu saldo positivo, enquanto o Sergipe passou de pequenas taxas negativas para pequenas taxas positivas de migração (IBGE, 2013).

Em contrapartida, a região Sudeste, considerando que, historicamente, foi uma região de grandes fluxos migratórios, apresentou mudanças nos seus fluxos migratórios que auxiliam a contextualizar as mudanças nos fluxos migratórios nordestinos. Minas Gerais, que se constitui, assim como o Nordeste, numa região expulsora de população, apresentou taxas positivas no quinquênio 1995 - 2000 e taxas negativas no período 2005 - 2010. Nas demais UF do Sudeste, evidencia-se uma queda nas taxas de migração, mostrando que esses espaços não possuem

\footnotetext{
${ }_{1}^{1}$ As análises deste artigo privilegiaram o quesito censitário que indaga sobre o local de residência há cinco anos anteriores à data do Censo Demográfico. A informação tradicionalmente chamada de "data fixa" permite a estimativa de fluxos migratórios ocorridos nos cinco últimos anos da década e só foi incluída a partir do Censo Demográfico 1991. Enfim, embora haja estimativas censitárias de migrações interestaduais de anos anteriores e para se manter coerente com os cruzamentos da caracterização dos migrantes retornados e dos seus efeitos indiretos, não utilizaram-se dados retrospectivos.
} 
mais a mesma capacidade de atração populacional que possuíam em períodos anteriores.

Tabela 1. População migrante nos quinquênios 1995/200 e 2005 e 2010 para as regiões Nordeste e Sudeste/Brasil

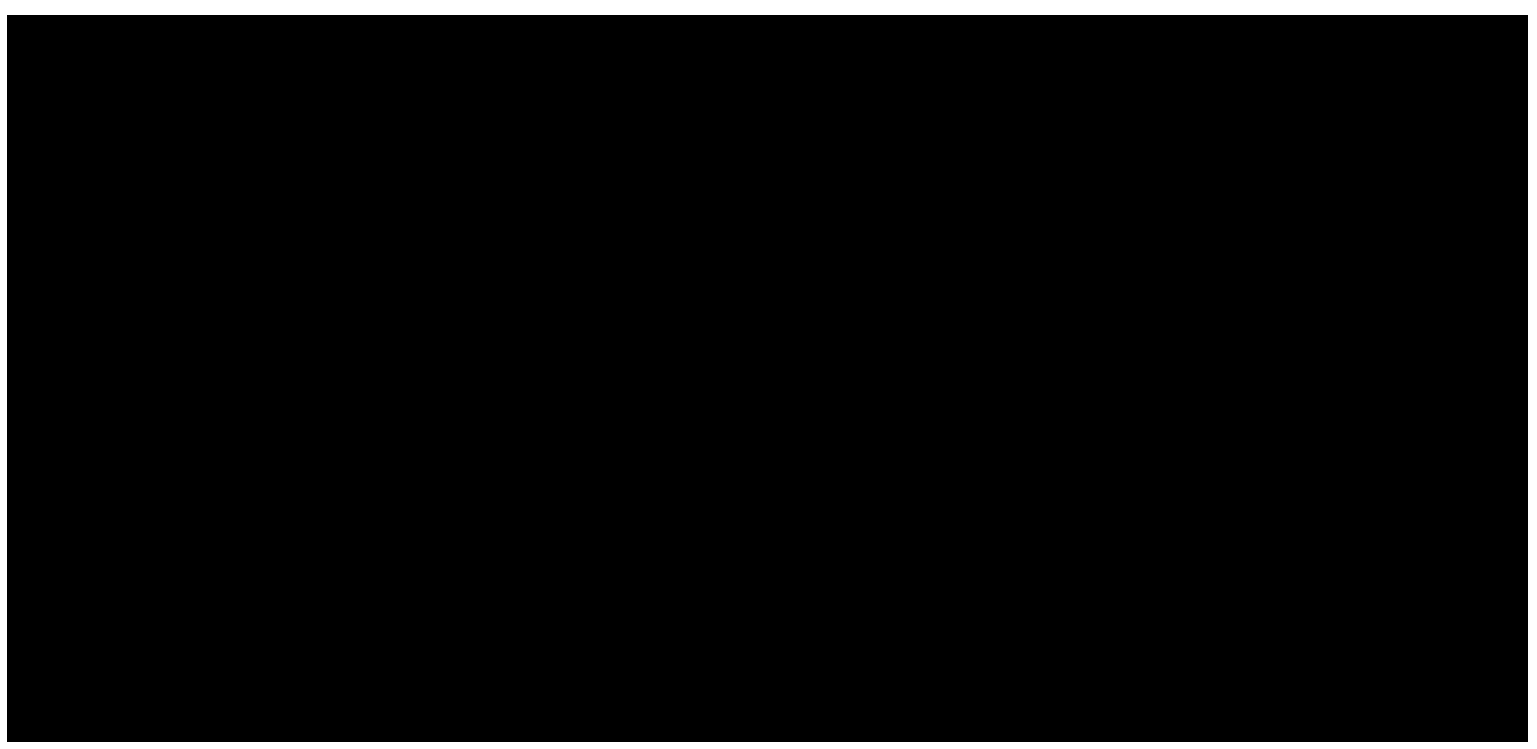

Fonte: IBGE, Censos Demográficos 2000/2010.

O Nordeste vem por um processo de transição urbana temporalmente diferenciada das demais regiões brasileiras, tornando-o singular em seus contextos migratórios e urbanos. A região é a menos urbanizada do país, mas na primeira década deste século, experimentou um intenso processo de urbanização. Diferentemente do que ocorreu em momentos anteriores na história da urbanização brasileira, esse processo se deu a despeito das grandes concentrações urbanas e dos fluxos migratórios polarizados (OJIMA, 2013). Nesse sentido, a migração de retorno e os fluxos migratórios intrarregionais jogam um papel decisivo.

Através dos dados do Censo Demográfico de 1970 já se podia perceber a mudança nos fluxos de migração interna como parte da transição demográfica brasileira. Nos anos 1980 já se apresentaria um significativo movimento nos fluxos migratórios de retorno em direção ao Nordeste (RIBEIRO, CARVALHO, WONG, 1996) e essas mudanças nos fluxos migratórios acompanham as alterações nas formas de acumulação econômica e dos espaços urbanos. Assim, passamos a ter uma atratividade migratória das cidades pequenas e médias, que são elementos fundamentais para compreendermos a migração de retorno para o Nordeste brasileiro.

Embora grande parte do incremento populacional nas cidades médias devase ao crescimento dos centros intermediários pertencentes às regiões metropolitanas (CARVALHO, 2003), na região Nordeste será possível perceber a polarização de núcleos locais sem conexão direta com as capitais e regiões metropolitanas. Isso pode ser observado a partir da intensificação, inclusive, dos fluxos de deslocamentos pendulares entre municípios pequenos e médios do interior nordestino e do país (OJIMA; MARANDOLA JR, 2012). 


\section{NOVAS TENDÊNCIAS: A MIGRAÇÃO DE RETORNO}

A migração é um fator que, historicamente, desempenhou um papel importante no desenvolvimento regional do país e, dentre os diversos tipos de migração, encontra-se a migração de retorno, isto é, uma volta que teria múltiplas motivações, entre elas, o desejo da segurança após a não adaptação no local de destino. Um retorno por fracasso migratório ou o anseio de culminar exitosamente com uma trajetória migratória de sucesso (RIBEIRO, CARVALHO, WONG, 1996). Os migrantes bem sucedidos que conseguem êxito no local de destino e retornam ao local de origem com as benesses adquiridas no processo migratório, ou retornam ao local de origem porque o processo migratório não supriu com as suas expectativas e ele precisa retornar ao local onde ele estabeleceu suas redes.

Embora complexo, diferencia-se aqui a migração de retorno da ideia de corrente e contra-corrente proposta por Ravenstein (1980), pois este último não implica, necessariamente, o retorno do mesmo indivíduo ao seu local de origem, mas fluxos complementares entre origens e destinos interligados. Assim, a migração de retorno deveria ser aquela nova etapa migratória na qual o mesmo indivíduo que realizou um movimento migratório anteriormente, retorna ao seu local de origem.

É possível perceber que, nas duas primeiras décadas deste século, há uma inversão significativa nos fluxos migratórios de retorno para o Nordeste. Embora o Nordeste ainda apresente perdas migratórias para outras regiões do país, a migração do Nordeste em direção ao Sudeste vem diminuindo sua intensidade e alguns estados do nordeste já vêm apresentando um saldo positivo (OJIMA, 2012). Tem-se um arrefecimento da capacidade de absorção dos estados do Sudeste concomitante com um maior dinamismo econômico da região nordeste, as novas atividades econômicas surgidas e o crescimento das cidades médias também são fatores que fazem com que os migrantes nordestinos voltem a sua região de origem e influencie o crescimento dessas cidades.

O retorno das migrações possui duas características básicas. A primeira é a fundamentação simbólica de todo e qualquer projeto migratório; e a segunda, desempenha uma função estrutural na topologia de um sistema de migração que, muitas vezes, o particulariza num dado contexto (FAZITO, 2010). Trata-se de não reduzir o discurso em simplesmente afirmar que todo fluxo migratório gera um contrafluxo (LEE, 1966). Trata-se de analisar as migrações de retorno como parte de um processo mais amplo, influenciados e influenciado por um conjunto de relações de produção e relações simbólicas que dão forma a este tipo de migração que possui características distintas da migração de retorno observada nas décadas de 1970 e 1980.

No território brasileiro, os migrantes de retorno 2 eram 1.144 .211 pessoas no período referente a 1995-2000 e 999.659 no período 2000-2005, representando $22 \%$ e $21,5 \%$ no total de imigrantes para o país, respectivamente (IBGE, 2013). Desse modo, cabe observar que a migração de retorno é um tipo de migração bastante expressiva no país e que vem se mantendo como uma forma

\footnotetext{
${ }^{2}$ A migração de retorno foi mensurada tomando-se por base a informação daqueles indivíduos que nasceram na Unidade da Federação em que residiam em 2010, e que moravam em outra UF há exatamente 5 anos da data de referência do Censo (IBGE, 2013).
} 
constante nos seus fluxos populacionais. Cabe ressaltar que a região Nordeste possui uma importância singular nessa discussão, pois suas UF, nos períodos de 2000 e 2010, apresentam as maiores proporções de retornados quando comparados com as demais regiões do país.

Tabela 2. Imigrantes de retorno e participação relativa, segundo as Unidades da Federação - 1995/2000 e 2005/2010

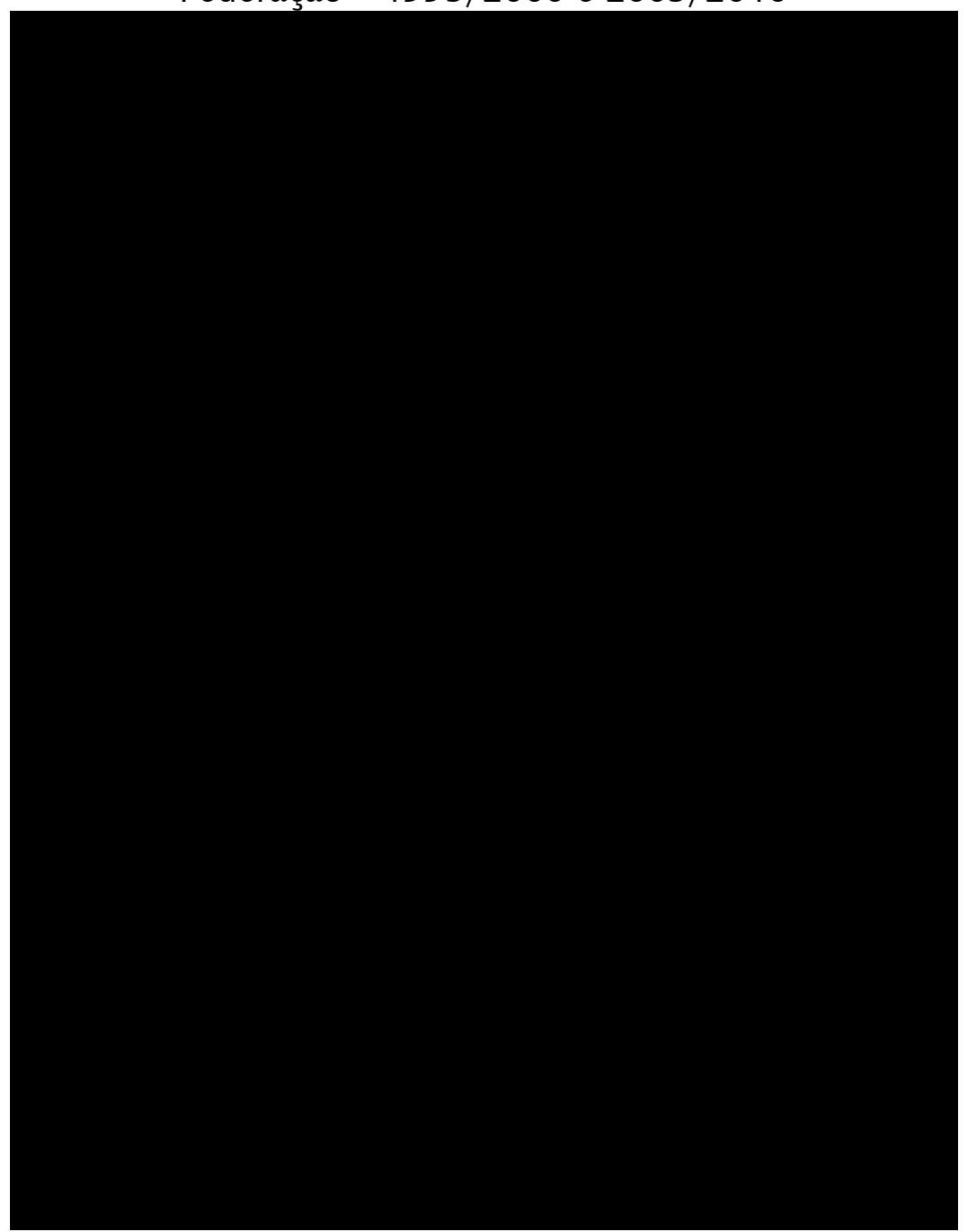

Fonte: IBGE, Censos Demográficos 2000/2010.

A migração de retorno constitui-se, então, como uma tendência para as UF brasileiras. Os estados da região Norte apresentam uma participação não tão expressiva como as UF nordestinas, mas com uma tendência crescente. Nas UF do sudeste o número de retornados decresceu, com a exceção do Estado de São Paulo. O decréscimo no número de retornados também é evidenciado na região Sul, com exceção do Rio Grande do Sul, e, no Centro-Oeste, há um aumento no número de migrantes de retorno.

A partir dos dados sobre migração de retorno (Tabela 2), observa-se as altas taxas proporcionais de migração de retorno para o Nordeste. Para os estados do Ceará e Paraíba, os migrantes de retorno representam mais do que $40 \%$ de todos os imigrantes que chegaram aos estados entre 2005 e 2010. De certo modo, esse processo se dá como resultado de suas altas taxas de emigração nas décadas 
anteriores. Assim, pode-se dizer que um sistema de migração se define pela associação e sobreposição de diferentes "redes migratórias": especificamente, "redes de fluxos" e "redes sociais". Enquanto a rede de fluxos representa a estrutura topológica bruta e abstrata de um sistema, a rede social representa a topologia sensível e correspondente ao contexto histórico-social do qual faz parte (Fazito, 2010). As redes sociais estabelecidas nos fluxos migratórios anteriores e atuais são elementos que contribuem para a manutenção de altas taxas de retorno no nordeste.

\section{O EFEITO INDIRETO DA MIGRAÇÃO DE RETORNO}

Mas a informação censitária usualmente utilizada para mensurar a migração de retorno leva em consideração apenas os indivíduos que retornaram à sua UF de nascimento entre 2005 e 2010, mas provenientes de outra UF. Considerando as questões simbólicas e de redes sociais envolvidas nesses processos, seria possível caracterizar a migração de retorno a partir de outras combinações de quesitos censitários como, por exemplo, o retorno exatamente ao mesmo município de nascimento ou até mesmo o retorno mais imediato ao último município de residência. Mas uma análise que não se leva muito em consideração nos estudos tradicionais dos efeitos da migração de retorno é o efeito indireto desses indivíduos retornados (RIBEIRO, CARVALHO, WONG, 1996).

Os efeitos indiretos da migração devem ser considerados, pois podem impactar de maneira significativa os volumes de imigrantes de uma determinada região, principalmente, quando as taxas de fecundidade total dos imigrantes são mais elevadas do que a da população que recebe estes migrantes. Nesse sentido, costuma-se considerar os filhos nascidos de imigrantes após o movimento migratório, uma vez que este filho de imigrante não seria contabilizado como migrante e tampouco teria nascido naquela região caso o imigrante não tivesse migrado.

Entretanto, considerando a migração de retorno, há um tipo de efeito indireto que é muito mais expressivo do que apenas considerar os filhos dos migrantes retornados na região de destino. Trata-se dos migrantes que acompanham o migrante de retorno, ou seja, aqueles que são contabilizados como migrantes comuns por não estarem retornando à sua UF de nascimento, mas que, ao acompanharem o migrante de retorno, tornam-se parte de um efeito indireto desses migrantes (RIBEIRO, CARVALHO, WONG, 1996; RIBEIRO, 1997; MAGALHÃES, 2003; GARCIA; RIBEIRO, 2004). Um exemplo dessa situação é o indivíduo que migrou do Nordeste para o Sudeste e, após estudar, trabalhar, casar-se e ter filhos por lá, retorna ao Nordeste com seu cônjuge e filhos. Esse cônjuge e filhos podem ser nascidos no Sudeste e, portanto, serão contabilizados como imigrantes diretos para o Nordeste. Entretanto, sua migração foi condicionada pelo retorno de um dos membros do domicílio, esse sim, retornado. 


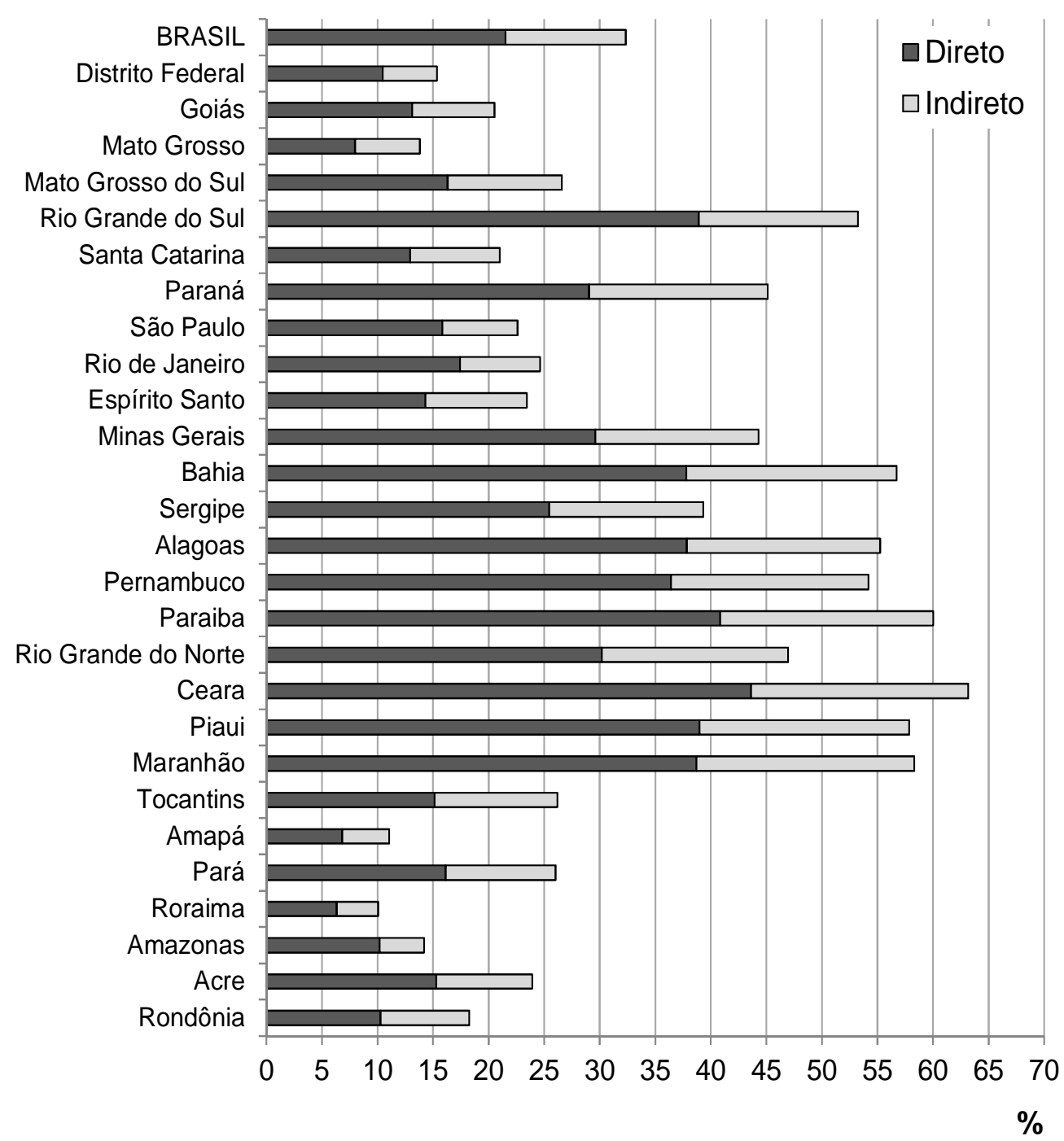

Figura 1. Participação relativa dos imigrantes de retorno e do efeito indireto da migração de retorno no total de imigrantes por Unidades da Federação, 2005/2010.

Fonte: IBGE, Censo Demográfico 2010.

A metodologia para analisar esse efeito indireto da migração de retorno é uma adaptação do trabalho elaborado por Ribeiro, Carvalho e Wong (1996). Considerou-se, portanto, como efeito indireto da migração de retorno, a existência de migrantes conviventes em domicílios de migrantes retornados e não foram, para este estudo, considerados os efeitos indiretos provenientes dos nascimentos ocorridos após a etapa migratória de retorno, que consisitiria em naturais da UF, mas filhos de retornados. Assim, pode-se observar que a migração de retorno que já apresenta peso significativo no total de imigrantes do Nordeste, torna-se mais expressiva ainda se considerado o seu efeito indireto. Mais de 500 mil imigrantes estão associados a quase 1 milhão de retornados identificados pelo Censo Demográfico 2010, passando de uma participação de 21,5\% para 32,3\% no total dos imigrantes do país.

Pode-se perceber que é nos estados do Nordeste que aumenta consideravelmente o peso relativo da migração de retorno quando considerado o seu efeito indireto, sendo que apenas o Sergipe e o Rio Grande do Norte não ultrapassam a marca de $50 \%$ da contribuição da migração de retorno no total dos 
imigrantes. Destaca-se o caso do Ceará que apresenta cerca de $63 \%$ de retornados (mais o efeito indireto) entre os imigrantes que viviam neste estado em 2010 e residiam em outra UF em 2005. Assim, juntamente com o estado do Maranhão, o Ceará é aquele que apresenta o maior percentual de contribuição de efeito indireto da migração de retorno $(19,6 \%)$.

Nos domicílios onde o responsável pelo domicílio é o próprio migrante retornado, o efeito indireto concentra-se em relações de parentesco próximas. Sendo 31\% composto de cônjuges, 32\% de filhos do casal e mais 19\% filhos apenas do migrante retornado. Essa constatação permite inferir que a migração de retorno tende a trazer consigo a sua familia nuclear como parte principal do efeito indireto, ou seja, são maridos/esposas e filhos os principais imigrantes que acompanham o retornado.

Migrantes de Retorno

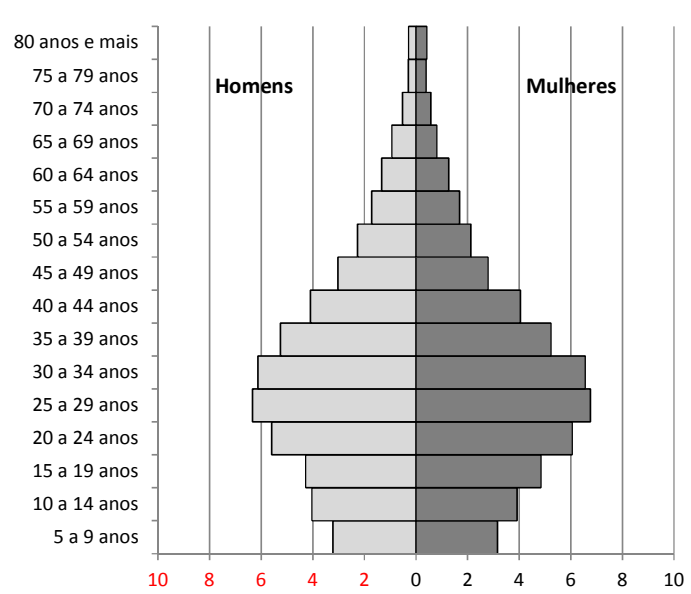

\section{Efeitos Indiretos}

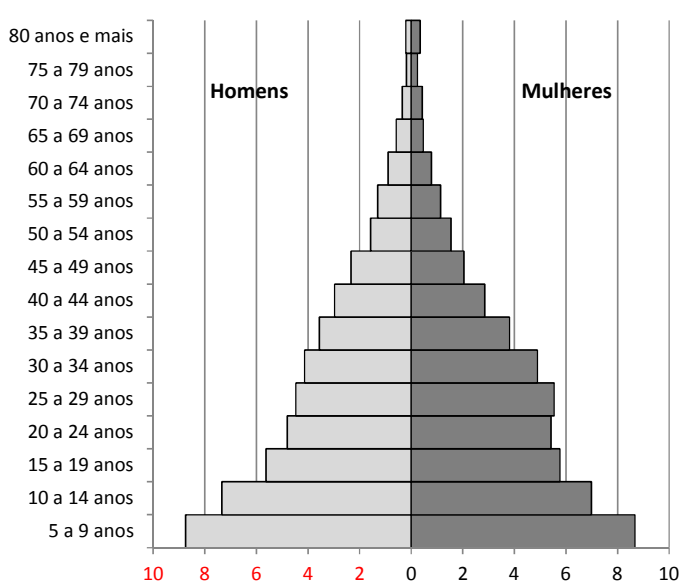

Figura 2.Estrutura etária e sexo dos migrantes de retorno e do efeito indireto, Brasil - 2005/2010. Fonte: IBGE, Censo Demográfico 2010.

O perfil do arranjo domiciliar do migrante retornado e responsável pelo domićlio confirma a distribuição etária diferenciada entre o migrante de retorno e de seu efeito indireto. Essa seletividade migratória estaria relacionada a essas características particulares do retorno. Ou seja, o migrante de retorno tende a ter uma média de idade mais avançada do que se considerados os migrantes não retornados e, em vista dos efeitos indiretos da migração de retorno, essa tendência é perceptível através da Figura 2. Isso significa que, para parte desses retornados, a migração foi bem sucedida durante a sua trajetória migratória, permitindo trazer consigo sua familia. Assim, é possível que esse migrante tenha adquirido maior escolaridade, retornando mais apto ao mercado de trabalho em sua UF de nascimento. Nesse caso, ele volta com melhores condições de vida, podendo prosperar no seu lugar de origem (BAPTISTA, CAMPOS, RIGOTTI, 2012). 
Nos caminhos para o Nordeste: reflexões sobre os impactos diretos e indiretos da migração...

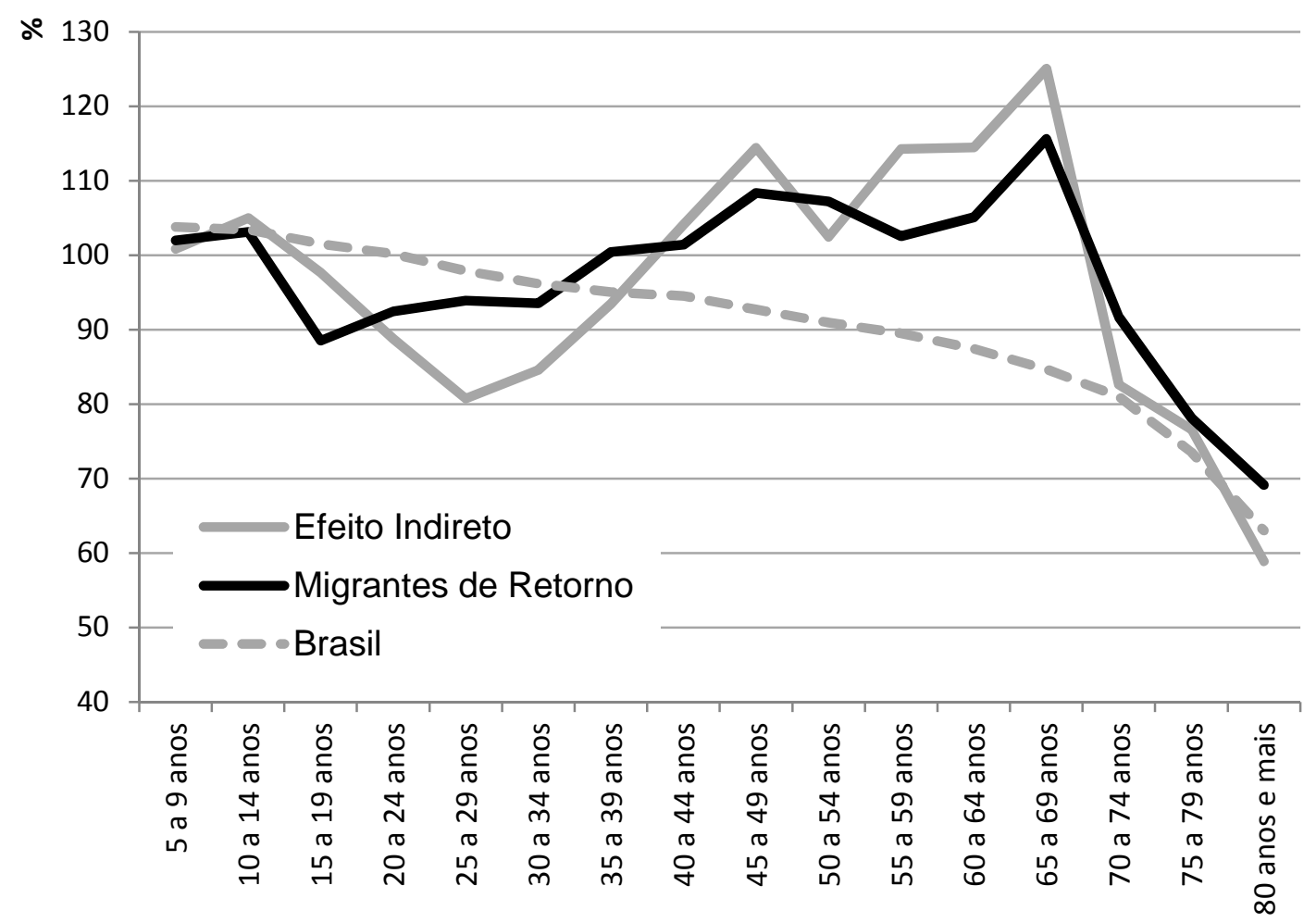

Figura 3. Razão de $\operatorname{sexos}^{3}$ dos migrantes de retorno e do efeito indireto, Brasil - 2005/2010. Fonte: IBGE, Censo Demográfico 2010.

É possível perceber, ainda, que há uma participação maior de homens nas idades mais avançadas tanto no que se refere à migração de retorno como nos efeitos indiretos. A partir do grupo de idade de 40 a 44 anos até 70 a 74 anos de idade, é muito expressiva a seletividade masculina da migração de retorno e do efeito indireto. Por outro lado, nas idades mais jovens, dos 15 aos 34 anos, principalmente, a quantidade de mulheres supera a de homens. A Figura 3 mostra a razão de sexos que é medida pelo quociente entre o volume de homens pelo de mulheres em cada grupo de idade que, se comparado aos dados da população brasileira, permite perceber a seletividade por sexos muito diferenciada de acordo com as idades. Em termos de escolaridade, tanto os migrantes de retorno como o efeito indireto apresentam similaridades. Destaca-se o fato de que, em ambos os casos, a proporção de migrantes com curso superior ou mais é de mais de $17 \%$, o que confirma a hipótese de maior escolaridade obtida ao longo de sua trajetória migratória.

Como apontado por Oliveira e Jannuzzi (2005), os motivos da migração de retorno são mais expressivos para a categoria de acompanhamento da família. Nesse sentido, tende a se confirmar a hipótese de que as relações de parentesco desempenham papel fundamental nos fluxos migratórios de retorno. Portanto, a composição de arranjos domiciliares decorrentes dos efeitos indiretos da migração

\footnotetext{
${ }^{3}$ Obtida a partir do quociente entre homens e mulheres (multiplicado por 100) em cada grupo etário. Assim, razão de sexos em torno de 100, representa equilíbrio entre homens e mulheres nessa subpopulação, portanto, valores acima de 100 indicam mais homens do que mulheres naquele grupo etário.
} 
de retorno pode ser um dos elementos fundamentais para o entendimento do impacto social e econômico que o aumento de importância do retorno pode ter na dinâmica regional, sobretudo, quando o retorno se dá para novas centralidades fora das capitais nordestinas.

De uma região de hegemônicas perdas populacionais, o surgimento de novos polos de atração na região Nordeste passa a apresentar outras dinâmicas econômicas e sociais. Aspectos associados às políticas de transferência de renda governamental como o Programa Bolsa Família-PBF podem ser elementos subjacentes nesse novo cenário, pois, com o ingresso no PBF, os beneficiários passaram a contar com acesso a crédito informal junto aos comerciantes locais (WEISSHEIMER, 2010; REGO; PINZANI, 2013), favorecendo a criação de mecanísmos de mercantilização das redes de proteção da reprodução social imediata.

Considera-se que o PBF tem efeito positivo na retenção e/ou fixação de migrantes no semiárido setentrional (OJIMA; COSTA; CALIXTA, 2014). Os programas de transferência de renda podem, também, constituir-se em um mecanismo de estímulo ao retorno migratório, pois permitem que o beneficiário busque local de residência que reduza seu custo de vida, retorne ao grupo familiar expandido ou simplesmente escolham residir em regiões mais tranquilas para um determinado estilo de vida (CAMPOS; BARBIERI; CARVALHO, 2008; OLIVER, 2008). Dessa forma, incentivariam o retorno migratório em direção às pequenas $e$ médias cidades em regiões antes consideradas expulsoras da população (OJIMA; OLIVEIRA; AZEVEDO, 2015), alterando as dinâmicas regionais.

\section{CONSIDERAÇÕES FINAIS}

Se trabalho e família (...) constituem duas questões-chave para 0 entendimento do processo de migração de retorno" (LYRA, 2014), quando as condições materiais são equacionadas por meio dos mecanismos de proteção social, torna-se preponderante o papel das redes familiares. Mas, mesmo que essa dinâmica de retorno possa ser efêmera e dependente de transferência governamental, é evidente que tem um impacto na dinamização das economias locais e, portanto, poderão apresentar efeitos permanentes no desenvolvimento econômico da região.

Ou seja, a migração de retorno, pode ser entendida como um processo de busca das identidades culturais pelo migrante, mas tem potencial para se tornar um mecanismo de compensação retroativo aos movimentos migratórios de décadas anteriores. A migração de retorno, portanto, não é apenas um processo que ganha destaque pelos volumes quantitativos, mas, principalmente, pela qualificação e seletividade do perfil sociodemográfico desse migrante.

A partir da metodologia proposta neste trabalho, analisaram-se apenas os fluxos de migração de retorno recentes (1995-2000 e 2005-2010), pois se privilegiou a análise a partir do quesito de "data fixa", que permite uma análise mais segura acerca da temporalidade e localidade dos fluxos migratórios. Trabalhos futuros poderiam aprofundar análises a partir de outros quesitos censitários relativos à migração de modo a entender a evolução retrospectiva desses processos. Tal abordagem permitiria analisar mais detalhadamente 0 
impacto que políticas sociais podem trazer aos fluxos migratórios e ao desenvolvimento regional decorrente deles. Estudos nessa direção vêm sendo desenvolvidos para o recorte do semiárido setentrional e apontam para respostas interessantes e coerentes a este estudo ${ }^{4}$.

Outra perspectiva para estudos futuros é a identificação dos efeitos indiretos de modo a caracterizar os arranjos domiciliares envolvidos nos domicílios de migrantes e suas características socioeconômicas. Enfim, os resultados apresentados neste artigo permitem confirmar a importância de estudos que relacionem migrações e arranjos familiares. É certo que as migrações contemporâneas possuem muitas nuances que ainda merecem mais aprofundamentos, pois, aparentemente, os fluxos são menos homogêneos e relacionados a mais variáveis contextuais que não apenas os fluxos econômicos.

\section{REFERÊNCIAS}

ANDRADE, M.C. A terra e o homem no nordeste: contribuição ao estudo da questão agrária no nordeste. São Paulo Ed. Cortez, 2011.

ARAÚJO, T.B. Ensaios sobre o desenvolvimento brasileiro: heranças e urgências. Rio de Janeiro: Ed. Revan, 2000.

BAENINGER, R. Rotatividade migratória: um novo olhar para as migrações no século XXI. Anais... XVI Encontro Nacional de Estudos Populacionais. Caxambu: ABEP, 2008.

BAENINGER, R.; OJIMA, R. Novas Territorialidades e a Sociedade de Risco: Evidências empíricas e desafios teóricos para a compreensão dos novos espaços da migração. Papeles de Población, v. 14, p. 141-154, 2008.

BAPTISTA, E. A. CAMPOS, J. RIGOTTI, J.I.R. Migração de retorno ao Brasil nos qüinqüênios 1986/1991, 1995/2000 e 2005/2010. In: XVIII Encontro Nacional de Estudos Populacionais, ABEP, Águas de Lindóia-SP, 2012.

BRASIL. Ministério do Planejamento, Orçamento e Gestão. Instituto Brasileiro de Geografia e Estatística. Censo Demográfico 2010. Resultados Gerais da Amostra, errata migração, 2013.

BRITO, F. As migrações internas no Brasil: um ensaio sobre os desafios teóricos recentes. Texto para discussão n.366. CEDEPLAR, 2009.

CAMPOS, M.B.; BARBIERI, A.F.; CARVALHO, J.A.M. Migração e Previdência Social no Brasil entre 1980 e 2000. In: Mudança populacional: aspectos relevantes para a Previdência - Brasília : MPS, SPPS, 2008.

\footnotetext{
${ }^{4}$ Projeto: "Impacto dos Programas de Transferência de Renda sobre a Dinâmica Populacional e Redução da Pobreza no Semiárido Setentrional Nordestino" (CHAMADA MCTI-CNPq/MDS-SAGI No 24/2013 - DESENVOLVIMENTO SOCIAL).
} 
CANELAS, R.G.V. Migração e mobilidade social na sociedade nordestina. São Paulo. FEA/USP. Dissertação de Mestrado. 1980.

CARVALHO, E. Exclusão social e crescimento das cidades médias brasileiras. Scripta Nova. Barcelona, Vol. VII, num. 146(128), 1 de agosto de 2003.

CARVALHO, J.A.M. RIBEIRO, J.T.L. A imigração para Minas Gerais no período de 1981/1991, com especial enfoque na migração de retorno. Rev. Bras. Estudos Pop. Brasília, 16. n. 1/2 jan./dez. 1999.

CUNHA, J.M.P. Mobilidade espacial da população: desafios teóricos e metodológicos para o seu estudo. Campinas: Ed. Nepo/Unicamp, 2011.

FAZITO, D. Análise de redes sociais e migração: dois aspectos fundamentais do "retorno". Revista brasileira de ciências sociais. Vol. 25, n72, fevereiro/2010.

FOUCAULT, M. Segurança, território, população: curso dado no Collège de France (1977-1978). São Paulo: Ed. M. Fontes, 2008.

GARCIA, R. A.; RIBEIRO, A. de M. Movimentos migratórios em Minas Gerais: efeitos diretos e indiretos da migração de retorno - 1970/1980, 1981/1991 e 1990/2000. In: XI Seminário sobre a Economia Mineira, 2004, Diamantina, Anais... Belo Horizonte, 2004, p. 15.

GIDDENS, A. As conseqüências da modernidade. São Paulo: Ed. UNESP, 1991.

HARVEY, D. A condição pós-moderna. São Paulo: Edições Loyola, 2000.

LEE, E. $A$ theory of migration. Demography, Vol. 3, n¹. pp. 47-57, 1966.

LEFEBVRE, H. O direito à cidade. São Paulo: Ed. Centauro, 2009.

LYRA, Maria Rejane Souza de Britto. Sulanca X Muamba: rede social que alimenta a migração de retorno. São Paulo Perspec., São Paulo, v. 19, n. 4, Dec. 2005. Disponível em: < http://ref.scielo.org/5zyxfs>. Acesso em: 08 mar. 2014.

MAGALHÃES, M.V. O Paraná e suas regiões nas décadas recentes: as. migrações que também migram. Tese de Doutorado. Belo Horizonte: CEDEPLAR /UFMG, 2003.

MARANDOLA Jr, E. OJIMA, R. Mobilidade populacional e um novo significado para as cidades: dispersão urbana e reflexiva na dinâmica regional não metropolitana. R. B. Estudos Urbanos e Regionais. v. 14, n. 2/Nov. 2012.

MASSEY, D. Pelo Espaço: uma nova política da espacialidade. Rio de Janeiro: Ed. Bertrand Brasil, 2012. 
OJIMA, R. As migrações recentes no Rio Grande do Norte: notas sobre um estado ganhador. Cadernos de Estudos Sociais, v. 27, p. 147-154, 2012.

OJIMA, R. Urbanização, dinâmica migratória e sustentabilidade no semiárido nordestino: o papel das cidades no processo de adaptação ambiental. Cad. Metrop. São Paulo, v.15, n. 29, pp 35-54, jan/jun 2013.

OJIMA, R. ; COSTA, J.V. ; CALIXTA, R. K. . Minha vida é andar por esse país...: a emigração recente no semiárido setentrional, políticas sociais e meio ambiente. REMHU (Brasília), v. 22, p. 149-167, 2014.

OJIMA, R.; OLIVEIRA, H.C.G.; AZEVEDO, P.R.M. O impacto da aposentadoria no retorno migratório ao Rio Grande do Norte e ao semiárido potiguar. Informe Gepec (Impresso), v.19, n.1, 2015.

OLIVEIRA, F. A economia brasileira: crítica a razão dualista. Rio de Janeiro: Ed. Vozes, 1987.

OLIVEIRA; K.F.; JANNUZZI, P.M. Motivos para migração no Brasil e retorno ao Nordeste: padrões etários, por sexo e origem/destino. São Paulo em Perspectiva. V.19, n.4, p134-143, out/dez, 2005.

OLIVER, C. Retirement migration: paradoxes of ageing. New York/London: Routledge. 2008.

PASTORE, J. Desigualdade e mobilidade social no Brasil. São Paulo: TA Queiroz/EDUSP, 1979.

REGO, W.L.; PINZANI, A. Vozes do Bolsa Família: autonomia, dinheiro e cidadania. São Paulo: Ed. Da Unesp, 2013.

RIBEIRO, J.T.L. CARVALHO, J.A.M. WONG, L.R. Efeitos demográficos da migração de retorno: uma proposta metodológica. In: X Encontro Nacional de Estudos Populacionais, 1996. ABEP, 1996.

RIBEIRO, J.T.L. CARVALHO, J.A.M. WONG, L.R. Migração de retorno: algumas possibilidades de mensuração. In: X Encontro Nacional de Estudos Populacionais, 1996. ABEP, 1996.

RIBEIRO, José Teixeira Lopes. Estimativa da migração de retorno e de alguns de seus efeitos demográficos indiretos no nordeste brasileiro, 1970/1980 e 1981/1991. Belo Horizonte: CEDEPLAR: Tese de Doutoramento, 1997. 206 p.

RIGOTTI, J.I.R. Información de los censos demográficos Del Brasil sobre migraciones internas: críticas y sugerencias para El análisis. Notas de poblácions n०88. CEPAL. 
SANTOS, M. A natureza do espaço: técnica e tempo, razão e emoção. São Paulo: Ed. EDUSP, 2009.

SILVA, J.G. A nova dinâmica da agricultura brasileira. Campinas: Ed. UNICAMP, 1998.

WEISSHEIMER, M.A. Bolsa família: avanços, limites e possibilidades do programa que está transformando a vida de milhões de famílias no Brasil. São Paulo: Ed. Fundação Perseu Abramo, 2010.

Submetido em: 08/03/2014.

Aprovado em: 22/07/2015.

\section{Sobre os autores}

Ricardo Ojima

Sociólogo e Doutor em Demografia

Professor do Departamento de Demografia e Ciências Atuariais - DDCA/Universidade Federal do Rio Grande do Norte - UFRN.

Endereço: Campus Universitário UFRN, Av. Salgado Filho, s/n - Lagoa Nova. 59.072-900 - Natal, RS, Brasil.

E-mail ricardo.ojima@gmail.com

\section{Tiago Carlos Lima do Nascimento}

Geógrafo e Mestre em Demografia

Doutorando em Demografia, Centro de Desenvolvimento e Planejamento Regional - Cedeplar/ Universidade Federal de Minas Gerais - UFMG.

Endereço: Rua dos Aeronautas, 322 - Ap. 29 - Pampulha. 31.270-320 - Belo Horizonte, MG, Brasil.

E-mail tiago.tcln@gmail.com 